\title{
Impact of Maintaining L1 Reading Skills on L2 Reading Skill Development in Adults: Evidence from Speakers of Serbo-Croatian Learning French
}

\author{
FRANÇOIS PICHETTE \\ Department of World Language \\ Education \\ College of Arts Ẽ Sciences \\ University of South Florida \\ 4202, East Fowler Avenue, \\ CPR 419 \\ Tampa, FL 33620-5550 \\ Email: pichette@chuma1.cas. \\ usf.edu
}

\author{
NORMAN SEGALOWITZ \\ Department of Psychology \\ Concordia University \\ 7141 Sherbrooke Street West \\ Montréal, Québec \\ Canada H4B $1 R 6$ \\ Email: segalow@vax2.concordia.ca
}

\author{
KATHLEEN CONNORS \\ Département de linguistique et de \\ traduction \\ Université de Montréal \\ C.P. 6128, succursale Centre-ville \\ Montréal, Québec \\ Canada H3C 3J7 \\ Email: kathleen.connors@ \\ umontreal.ca
}

\begin{abstract}
Clarke (1980) hypothesized that effective interlingual transfer of reading skills requires the attainment of some particular threshold of second language (L2) knowledge. Results from a study by Hacquebord (1989) suggested that the interlingual transfer of reading skills also requires active reading of the first language (L1). Results from a longitudinal study carried out over a 1-year period with 52 Bosnians learning French as a L2 supported Clarke's hypothesis but were only partially in accord with Hacquebord's. Significant correlations between L1 and L2 reading performance for the subgroup of nonactive L1 readers suggested that failure to maintain L1 reading did not prevent the transfer of reading skills. However, the greater improvement in L2 reading ability by the active L1 readers than by the nonactive L1 readers suggested that maintaining L1 reading enhances the transfer of reading skills.
\end{abstract}

IN 1984, ALDERSON LAUNCHED A DEBATE as to whether problems in foreign language reading stem from reading problems or language problems. He suggested that methodological shortcomings of previous studies were responsible for results that pointed in both directions and stressed the need for further studies to clarify the situation. Since Alderson's article appeared, at least 10 studies have examined the relative influence of first language (L1) reading ability and second language (L2) knowledge

The Modern Language Journal, 87, iii, (2003) 0026-7902/02/391-403 \$1.50/0 C2003 The Modern Language Journal on L2 reading ability. In 1995, Bernhardt and Kamil reevaluated previously published data, which contributed to a resolution of Alderson's question. They concluded that the five studies that explicitly addressed the question (Bossers, 1991; Brisbois, 1995; Carrell, 1991; Hacquebord, 1989; Roller, 1988) pointed to the dominance of the L1 reading variable but that the range of estimates was too broad to allow for firm conclusions.

Bernhardt and Kamil (1995) also presented new data from 186 English speakers reading English and Spanish. In their data, language proficiency accounted significantly for over $30 \%$ of the variance in $\mathrm{L} 2$ reading scores, whereas $\mathrm{L} 1$ reading 
ability accounted significantly for more than $10 \%$ of the variance. The investigators concluded that neither variable mentioned by Alderson could alone fully explain the L2 reading process and that both were significant contributors. Other studies directly addressing the question have shown both variables to be significantly related to L2 reading (Fecteau, 1999; Lee \& LemonnierSchallert, 1997; Pichette, 1995; Taillefer, 1996; Wagner, Spratt, \& Ezzaki, 1989).

As Alderson (1984) pointed out, the variation in the relative influence of both factors from one study to the other can be explained by Clarke's (1980) well-known short-circuit hypothesis, also known as the language threshold hypothesis. According to this hypothesis, the reader has to reach a threshold of L2 knowledge in order to be able to transfer his or her reading skills effectively from the L1 to the L2; otherwise, insufficient knowledge of the L2 would "short circuit" the reader's reading system. This hypothesis suggests that the correlation between L1 and L2 reading scores should be nonsignificant for low knowledge learners, but beyond the hypothetical language threshold, the transfer should start showing itself in high and significant correlations between scores in L1 and L2 reading that increase as L2 knowledge improves.

With regard to the correlation between scores in $\mathrm{L} 1$ reading and L2 reading, a few studies have shown, as predicted above, a stronger correlation for advanced learners than for beginners (e.g., Bossers, 1991; Carrell, 1991). Other studies have shown no difference despite testing at various levels of L2 knowledge (e.g., Bernhardt \& Kamil, 1995; Taillefer, 1996). There is, however, one longitudinal study (Hacquebord, 1989, as cited in Bossers, 1991) ${ }^{1}$ showing the correlation between reading performance in the two languages to decrease as L2 knowledge improved, even to the point of becoming nonsignificant over time. This phenomenon, as suggested by Hacquebord, may be attributable to the fact that her participants had ceased reading their L1.

Hacquebord's (1989) interpretation suggests that the interlingual transfer of reading skills may require continued active reading of the language in which these skills first developed. That is, failure to maintain L1 reading may prevent the transfer of reading skills from the L1 to the L2. However, one must take into account the ages and the circumstances under which Hacquebord's participants learned their L2. They were Turkish immigrants to the Netherlands, for most of whom the L2 had replaced their L1 as the dominant language. This situation would have reversed the usual relationships between the variables L1 (dominant language) and L2 (nondominant language) and could explain why Hacquebord's results differed from those of earlier research. Furthermore, given their ages at the time of immigration, some of the younger language learners may possibly have developed their reading skills in their original L1 (Turkish) after learning to read in their L2 (Dutch). Given these considerations, it would likely be difficult to reproduce Hacquebord's results with adults. Nevertheless, there remains the possibility that reading skills are, in fact, not transferable in the case of learners who no longer read their L1. No prior studies have involved adults in that situation.

The main purpose of the present study was to examine Hacquebord's (1989) transfer hypothesis that reading skills have to be kept active in the L1 if they are to transfer to L2 reading. Accordingly, we addressed the following three closely related questions. First, concerning the basic phenomenon to be explained, is there a significant positive relationship between L2 reading ability and L1 reading ability, and between L2 reading ability and L2 knowledge? Second, concerning Clarke's (1980) short-circuit hypothesis, is L1 reading more strongly related to L2 reading ability among people with a high level of L2 knowledge than it is among those with a low level of L2 knowledge? Finally, regarding Hacquebord's transfer hypothesis, does the absence of L1 reading practice significantly affect the transfer of reading skills from L1 to L2?

We explored these questions in a longitudinal study involving Bosnians who had recently moved to a French-speaking milieu (Québec City). We tested them twice over a 1-year period for L1 reading ability (in Serbo-Croatian), L2 reading ability (in French), and L2 knowledge.

We assessed reading ability by means of cloze tests that were specifically developed for this research because no normed, comprehensive tests of reading ability were available in Serbo-Croatian, and the testing time did not permit extensive assessments of L2 reading abilities, as desirable as that may have been. Although some researchers consider cloze tests unsuitable as measures of the comprehension of long-range syntactic or semantic relations (e.g., Alderson, 1980; Shanahan, Kamil, \& Tobin, 1982), other researchers believe that they reflect a degree of global comprehension beyond the clause or sentence level, as well as knowledge of orthographic, morphological, and syntactic rules (Bachman, 1982; Chihara, Oller, Weaver, \& Chávez-Oller, 1977; Jonz, 1990). Proponents have also ad- 
dressed other criticisms of the cloze procedure regarding inconsistent results and other "technical” problems (see Jonz \& Oller, 1994; KleinBraley \& Raatz, 1984). Strong correlations between scores on cloze tests and scores on standardized reading comprehension tests have surfaced in research (Anderson, 1976; Bormuth, 1967). Cloze scores also discriminate among L2 readers (Brière, Clausing, Senko, \& Pincell, 1978; Cziko, 1978; Jonz, 1987). Among the advantages of the cloze procedure is that, unlike comprehension questions, it does not introduce additional information that can modify the reader's reasoning process. In addition, regular deletions ensure a set of items that is neutral with respect to the content of the text. Finally, the procedure is economical in terms of preparation, testing, and correcting time.

We operationalized the level of French L2 knowledge by using sections of the Test Laval (CIRB, 1976), an examination used in most Québec universities and elsewhere in Canada as an index of knowledge of French as a Second Language (FSL). The test is designed for nonFrancophone adolescents and adults of both sexes, with a high school education, who wish to study FSL or are already studying it. Its aim is to permit evaluation of a person's general knowledge of French and his or her disposition for studying FSL by assessing the comprehension of "sounds" (i.e., phoneme distinctions), words, and grammar rules. Measures of internal consistency of the sections of the Test Laval used in the present study have been reported to be .84 for both forms of the test used, and equivalence between the two forms has been reported as .87 for grammar and .92 for vocabulary (CIRB, 1976).

These instruments allowed us to obtain data reflecting the participants' L2 (French) knowledge, their L2 reading ability, their L1 reading ability, and the amount of time they spent reading in their L1. With these measures, we were able to answer the three questions above and to assess how the factors of $\mathrm{L} 1$ reading maintenance and L2 knowledge affected L2 reading ability over time.

\section{METHOD}

\section{Participants}

The participants were 26 men and 26 women, ranging from 17 to 47 years of age. All were Bosnians who had migrated to Québec from the former Yugoslavia. Serbo-Croatian was their L1. Their L2 was French, Québec's official language, and the one used in everyday life. At the time of the first series of tests (Time 1), the participants had been in Québec for a period ranging from 7 to 21 months. At the time of the second testing (Time 2), their time spent living in a French language environment ranged from 19 to 33 months.

All the participants had completed the Québec government's French language program and were enrolled in French courses for immigrants in a community school, where they were at level 4,5 , or 6 of the six possible levels with level 6 being the most advanced. They had sufficient knowledge of French to understand ordinary conversations and read simple texts. There appeared to be little variation among the participants in respect to level of education or socioeconomic status: All had completed high school, 3 held university degrees (in engineering, medicine, physics), all were unemployed at the time of testing. All had learned to read in the Roman alphabet, and having finished high school, they were presumably proficient readers in their L1. The participants were paid for their participation.

\section{Materials}

The materials for the study consisted of two cloze tests in Serbo-Croatian that we designed to measure L1 reading ability, and two cloze tests in French designed for this study to measure L2 reading ability. The texts used to develop these cloze tests are described below. There were also two versions of the above-mentioned test of L2 knowledge of French, with each version administered at two testing times. Finally, we used a questionnaire at Time 1 to collect information concerning the participants' backgrounds and their reading habits. We distributed a shorter version of the questionnaire at Time 2 to keep track of the reading times in both languages.

French Texts. The two French texts were excerpted from the Journal de Québec, a Québec City newspaper aimed at a readership of a low to average level of education. Both texts were relatively recent and concerned a general topic so as to minimize the possible effects of different readers' specialized content knowledge. We used Henry's (1975) readability formula for French, which assigns scores between 0 and 1 to texts, based on such factors as the number of words per sentence, the percentage of words that belong to a list of common words, and the percentage of words that serve as dialogue indicators. 
One text was about a man from Québec working as an alligator hunter in Louisiana (429 words, 24 sentences, mean of 17.9 words per sentence) and the other text described the world's oldest woman celebrating her 120th birthday (412 words, 23 sentences, mean of 17.9 words per sentence). We modified the texts slightly so that each would have exactly the same level of difficulty according to Henry's formula. According to Henry's optimal range of readability (0.35-0.45), each text was slightly too difficult for the last grade of elementary school (score of 0.35 each) and too easy for the last 2 years of the first part of high school (score of 0.57 and 0.58 ), which means that they were both suitable, in L1, for seventh-graders/12-year-old readers.

Serbo-Croatian Texts. The two Serbo-Croatian texts had appeared in Obzor (Hrvatski Obzor), a magazine published in Zagreb and intended for readers with a middle to high level of education. They too were relatively current, each on a topic of general interest. Given that there are no standardized readability formulas for Serbo-Croatian, we relied on the judgment of two native speakers of the language who were not participants in the study and one of whom was a linguist. We selected two texts whose vocabulary, grammar, and structure appeared difficult enough to differentiate adults in the reading of their L1. One text concerned the life and times of Boris Yeltsin (348 words, 20 sentences, mean of 17.4 words per sentence) and the other text was about Pope John Paul II traveling to several countries in North and South America (371 words, 17 sentences, mean of 21.8 words per sentence).

Reading Tests. In constructing cloze tests for the present research, we deleted every ninth word, judging that approximately 40 blanks were sufficient to provide a reliable measure of reading ability. Depending on the length of each text, the number of blanks varied from 34 to 41 . (It has been recommended that a cloze test have at least 25 items [Rand, 1978, as cited in Bachman, 1985].) When the word to be deleted happened to be either a number or a person's name, the following word was deleted instead, in order to avoid situations in which the ability to provide the correct answer would depend on pure chance or general culture (information retrieved from long-term memory), rather than on real reading comprehension. The first and last sentences were left intact so as to provide the reader with sufficient context. Finally, the participants had no choice of responses. They received one point for exact word replacement, even when it contained a spelling mistake. We divided the number of points by the maximum possible, the result of which yielded a percentage, in order to provide a comparable index for texts with different numbers of blanks.

Test of L2 Knowledge. The Test Laval served as the index of knowledge of French vocabulary and grammar and, thus, achievement in French. The grammar section of the test focuses on knowledge of morphosyntax, with emphasis on standard, as opposed to nonstandard and regional variants of, pronoun forms and clitic (personal pronoun) sequences, verb conjugation, concordance, subcategorization, and complementation properties, as well as agreement rules, including those that oppose written to oral French. The vocabulary section emphasizes derivational morphological relations, such as those of nouns with verbs, adjectives with adverbs, and adjectives with nouns. Together, these two sections contain 84 items concerning vocabulary and grammar. The test has three equivalent forms: A, B, and C. We used Forms B and C (CIRB, 1976) in the present study.

Questionnaire. The participants also answered a questionnaire about their experience in L1 and L2, including whether they had lived in a Francophone environment before, whether they had studied French before, and how much time per week they spent reading in each language. The questionnaire was in French and used simple vocabulary that the participants seemed to understand. They were to ask the administrator to explain any question they were not sure they understood.

\section{Procedures}

During the first session (Time 1), the participants were in small groups in a silent classroom. They were to try to answer all the questions without using reference materials (grammar, dictionary) or asking for any help. They were aware that it would be unusual to be able to answer every question on the French knowledge test, even if it had been their L1.

The participants first answered the questionnaire. Each participant subsequently took two cloze tests, one in the L1 and one in the L2, with the language order counterbalanced and quasirandomly assigned across participants and with the versions counterbalanced across Time 1 and Time 2. Between the two cloze tests, the participants took the Test Laval, Form B.

The participants underwent testing for the second time 1 year later. The directions and proce- 
dures were the same as they had been the first time. This time, however, the cloze test assigned for each language was the one they had not taken at Time 1, and the Test Laval was Form C. All the participants underwent the measures in isolation this time because they had all finished school and could not be reassembled at the same time and place.

The testing time for each session averaged 75 minutes, with a range of 50 to 100 minutes. There was no time limit for completing the tests or questionnaires.

\section{RESULTS AND DISCUSSION}

Despite the directions for the second series of tests, we eliminated the data of 2 participants who had obviously been helped and had helped each other to arrive at an almost perfect score in L2 knowledge and who had identical answers on a cloze test. Consequently, our analyses treated 50 cases (25 men, 25 women) for the first session. We had 43 (22 men, 21 women) for the second session, because 7 participants had left Québec between the sessions. We present the results below in relation to the three main questions identified earlier.

For all the analyses reported below, the level of confidence for rejecting a null hypothesis was .05 . We report actual $p$ values, however.

\section{Question 1}

Is there a significant positive relationship between $L 2$ and $L 1$ reading ability, and between $L 2$ reading ability and L2 knowledge?
Time 1 Tests. The mean cloze test score for L1 reading was $40.53 \%(S D=13.79)$ and for $\mathrm{L} 2$ reading it was $38.62 \%(S D=16.55)$. The mean L2 knowledge score (Test Laval) was 48.64 (out of a possible $84 ; S D=14.94)$. The participants reported reading in their $\mathrm{L} 1$ an average of 1.93 $(S D=4.77)$ hours per week and in the L2 10.65 $(S D=11.34)$ hours per week (see Table 1$)$.

These results indicate that the reading tests in the two languages were of similar level of difficulty for these subjects. Separate examination of the reading scores for each text provided a better picture of the difficulty level of each text used for each language. The cloze test means for the two French L2 texts $(39.8 \%$ of 39 items, $S D=16.1$; $37.3 \%$ of 41 items, $S D=17.3$ ) were not significantly different. In the case of the L1 Serbo-Croatian texts, however, the situation was somewhat different. Despite the native speakers' judgment of equivalence, one text was significantly more difficult than the other $(35.9 \%$ for the 39 items, $S D=11.6, n=24$ vs. $44.8 \%$ for the 34 items, $S D=14.46, n=26 ; t(48)=2.39, p=.021)$. The ranges of scores for these two versions were $10 \%$ to $54 \%$ and $12 \%$ to $68 \%$, respectively, which suggested no differential ceiling or floor effects.

Because it was important, for statistical purposes, for the texts to be comparable, all the data were normalized, separately for each text in each language, transforming the percentage scores to $z$-scores. Pearson correlation coefficients were calculated between the (normalized) cloze scores for L2 reading and those for L1 reading $(r=.511, p<.001)$ and the scores for L2 knowledge (Test Laval; $r=.647, p<.001$ ) using the entire sample of participants $(N=50)$. This result indicated that both L1 reading ability

TABLE 1

Descriptive Statistics: Measures of L1 Cloze, L2 Cloze, L2 Knowledge, and Reported Time Spent Reading L1 and L2 at Time 1 and Time 2

\begin{tabular}{lcc}
\hline \hline Variable & $M$ & $S D$ \\
\hline Time 1 (Whole Sample, $N=50)$ & & \\
L1 Reading Ability (Cloze Test) & $40.53 \%$ & 13.79 \\
Reading Ability (Cloze Test) & $38.62 \%$ & 16.55 \\
L2 Knowledge (Test Laval: Max. = 84) & $48.64^{\mathrm{a}}$ & 14.94 \\
Time Reported Spent Reading L1 (Hours per Week) & 1.93 & 4.77 \\
Time Reported Spent Reading L2 (Hours per Week) & 10.65 & 11.34 \\
Time 2 (Whole Sample, $N=43)$ & \\
L1 Reading Ability (Cloze Test) & $41.04 \%$ & 16.49 \\
L2 Reading Ability (Cloze Test) & $43.28 \%$ & 15.86 \\
L2 Knowledge (Test Laval: Max. = 84) & $51.77^{\mathrm{a}}$ & 16.25 \\
Time Reported Spent Reading L1 (Hours per Week) & 1.50 & 1.70 \\
Time Reported Spent Reading L2 (Hours per Week) & 8.21 & 7.93 \\
\hline
\end{tabular}

a These mean scores are significantly different by $t$ test, $p<.01$ (2-tailed test). 
and L2 knowledge were significantly associated with $\mathrm{L} 2$ reading ability.

A different picture emerged from a multiple regression analysis using L2 reading ability as the criterion variable and L1 reading ability and L2 knowledge as predictor variables (see Appendix, Part A, for basic data). This analysis accounted for a significant proportion of the variance of L2 reading ability $\left(R^{2}=.44, F=16.61, p<.001\right)$. Knowledge in the L2 (Test Laval) emerged as a significant factor $(\beta=.533, t=3.90, p=.001)$, but L1 reading ability (cloze test) did not $(\beta=$ $.189, t=1.39, p>.10$; see Table 2). No doubt, other social and psychological factors, such as fatigue, motivation, familiarity of the topic, context of the experiment, and so on, account for the rest of the variance (Carrell, 1991; Taillefer, 1996).

Time 2 Tests. As mentioned above, 43 of the original participants took the second series of tests 1 year after the first tests (Time 2). The mean cloze test score for $\mathrm{L} 1$ reading was $41.04 \%(S D=16.49)$ and, for $\mathrm{L} 2$ reading, $43.28 \%(S D=15.86)$. The mean L2 knowledge score (Test Laval) was 51.77 (out of a possible $84 ; S D=16.25$ ), a significant gain in knowledge over Time $1, t(42)=2.96, p=$ .005 , with 31 of the 43 participants demonstrating such gains. Mean number of hours per week reported for reading in the $\mathrm{L} 1$ was $1.50(S D=1.70)$ and in the L2 $8.21(S D=7.93)$.

As was the case at Time 1, these results revealed that the reading tests were of approximately equal difficulty for the two languages. For this second battery, we again tested the equivalence of the means for the two cloze tests in each language. The same Serbo-Croatian text was significantly more difficult than its counterpart. The participants' scores for all the tests were accordingly normalized, as described in the previous section, and reported henceforth as z-scores.

Pearson correlation coefficients for L2 and L1 reading ability scores $(r=.601, p<.001)$ and for L2 reading ability and L2 knowledge (Test Laval) scores $(r=.556, p<.001)$ suggested that both L1 reading ability and L2 knowledge predict L2 reading ability. In addition, multiple regression analysis, with L2 reading ability as the criterion variable and $\mathrm{L} 1$ reading ability and L2 knowledge as predictor variables, revealed that the two independent variables accounted for a significant proportion of the variance in L2 reading ability $\left(R^{2}=.45, F=16.41, p<.001\right.$; see Table 3; see Appendix, Part A, for basic data). Unlike the Time 1 analysis, however, both L1 reading ability $(\beta=.43, t=3.22, p=.003)$ and L2 knowledge $(\beta=.34, t=2.55, p=.015)$ emerged as significant factors.

In summary, at both Time 1 and Time 2, we found a significant positive association between L2 reading ability and L2 knowledge. Only at Time 2, when L2 knowledge was significantly greater than at Time 1, however, did we also find a significant relationship between L2 reading ability and L1 reading ability.

\section{Question 2}

Is $L 1$ reading more strongly related to $L 2$ reading ability among people with a high level of L2 knowledge than it is among those with a low level of L2 knowledge?

Here the issue is whether a high level of L2 knowledge is required for there to be a strong relationship between L1 and L2 reading abilities. To address this question, we divided the data into two clearly distinct, nonoverlapping subgroups on the basis of the participants' level of L2 knowledge. To obtain two groups that were as different as possible (highest and lowest thirds), we eliminated data for those participants whose Test Laval L2 knowledge scores were in the middle range, that is, between 8 points above and 8 points below the mean.

Time 1 Tests. For the first group of 50 participants, the mean L2 knowledge score on the Test

TABLE 2

Multiple Regression: L2 Reading Ability as a Function of L1 Reading Ability and L2 Knowledge at Time 1 (Whole Sample, $N=50$ )

\begin{tabular}{lcrcrl}
\hline \hline Variable & $\begin{array}{c}\text { Parameter } \\
\text { Estimate }\end{array}$ & $\beta$ & $t$ & $R^{2}$ & $F$ \\
\hline L1 Reading Ability & .19 & .189 & 1.39 & & \\
L2 Knowledge & .04 & .53 & $3.90^{* * * *}$ & .44 & $16.61^{* * * *}$ \\
\hline
\end{tabular}

Note. $d f=2$.

$* * * p<.001$. 
TABLE 3

Multiple Regression: L2 Reading Ability as a Function of L1 Reading Ability and L2 Knowledge at Time 2 (Whole Sample, $N=50$ )

\begin{tabular}{lccccc}
\hline \hline Variable & $\begin{array}{c}\text { Parameter } \\
\text { Estimate }\end{array}$ & $\beta$ & $t$ & $R^{2}$ & $F$ \\
\hline L1 Reading Ability & .43 & .43 & $3.22^{* *}$ & & \\
L2 Knowledge & .02 & .34 & $2.55^{*}$ & & \\
\hline
\end{tabular}

Note. $d f=2$.

$* p=.015 . * * p=.003 . * * * p<.001$.

Laval was 48.64 (out of a possible 84). Dividing the participants into two groups as described above yielded a 16-point spread between the highest "weak" participant and the lowest "strong" one: 17 participants scored below 41 $(M=32.35, S D=6.25$; henceforth, Low Knowledge or LoL2), and 16 participants scored above $57(M=66.06, S D=6.84$; henceforth, High Knowledge or HiL2).

For the data from Time 1, multiple regression analysis, with L1 reading ability and L2 knowledge as predictor variables and L2 reading ability as the criterion variable, revealed the following patterns. For the HiL2 participants (see Appendix, Part B), the two factors accounted for a relatively small proportion of the variance in L2 reading $\left(R^{2}=.28, F=2.53, p>.10\right.$; see Table 4$)$. Neither factor emerged as significant (L2 Knowledge: $\beta=.49, t=2.02, p=.064$; L1 Reading: $\beta=.13 ; t=.56, p>.10)$. In marked contrast, for the LoL2 participants (see Appendix, Part B), the two factors accounted for a significant proportion of the variance in $\mathrm{L} 2$ reading $\left(R^{2}=.56, F=9.06\right.$, $p=.003)$. The L2 knowledge predictor emerged as significant $(\beta=.525, t=2.57, p=.022)$, but the $\mathrm{L} 1$ reading predictor $\operatorname{did}$ not $(\beta=.33 ; t=$ $1.64, p>.10)$.

At first glance, these results do not appear to support the original expectation based on Clarke's (1980) short-circuit hypothesis that L1 reading ability is more strongly related to L2 reading ability among learners with higher L2 knowledge than it is among those with lower L2 knowledge. Instead, we found L1 reading to be a particularly weak predictor for the high knowledge group. Although failing to support Clarke's hypothesis, the data do not necessarily contradict it. One could speculate that perhaps many of the participants in the High Knowledge group did not yet have enough automaticity in L2 to transfer their reading skills and that this was the reason for the absence of a significant relation between L1 reading ability and L2 reading ability. Put another way, perhaps not enough of the

TABLE 4

Multiple Regression: L2 Reading Ability as a Function of L1 Reading Ability and L2 Knowledge at Time 1 for the High and Low L2 Knowledge Groups

\begin{tabular}{|c|c|c|c|c|c|}
\hline Variable & $\begin{array}{c}\text { Parameter } \\
\text { Estimate }\end{array}$ & $\beta$ & $t$ & $R^{2}$ & $F$ \\
\hline \multicolumn{6}{|l|}{$\begin{array}{l}\text { High L2 Knowledge } \\
(n=16)\end{array}$} \\
\hline L1 Reading Ability & .18 & .13 & .56 & \multirow[b]{2}{*}{.28} & \multirow[b]{2}{*}{2.53} \\
\hline L2 Knowledge & .05 & .49 & 2.02 & & \\
\hline \multicolumn{6}{|l|}{$\begin{array}{l}\text { Low L2 Knowledge } \\
(n=17)\end{array}$} \\
\hline L1 Reading Ability & .26 & .33 & 1.64 & \multirow[b]{2}{*}{.56} & \multirow[b]{2}{*}{$9.06 * * *$} \\
\hline L2 Knowledge & .07 & .53 & $2.57 *$ & & \\
\hline
\end{tabular}

Note. $d f=2$.

$* p=.022 . * * * p=.003$. 
members of the High Knowledge group had yet attained the threshold level referred to by Clarke (1980). Perhaps by Time 2, a year later, this situation had changed.

Time 2 Tests. The HiL2 and LoL2 knowledge groups were formed on the basis of the performance on the Test Laval, with a 16-point span around the mean score as described above. This time, the mean L2 knowledge was 51.77; hence, we categorized those participants scoring below $43(n=14)$ as LoL2 $(M=32.21, S D=7.47)$ and those participants scoring higher than $59(n=$ $18)$ as HiL2 $(M=67.11, S D=5.66)$.

Multiple regression analysis revealed the following patterns (see Appendix, Part C, for basic data). For the HiL2 group, the two factors together accounted for a significant proportion of the variance in L2 reading $\left(R^{2}=.50, F=7.61\right.$, $p=.005$; see Table 5). However, whereas L1 reading emerged as a significant predictor $(\beta=$ $.67, t=3.62, p=.003)$, L2 knowledge did not ( $\beta$ $=.14 ; t=.78, p>.10)$. For the LoL2 group, the two factors together accounted again for a significant proportion of the variance in L2 reading $\left(R^{2}=.68, F=11.90, p=.002\right)$. In contrast to the HiL2 participants, however, in the LoL2 participants' data, the L2 proficiency predictor emerged as significant $(\beta=.859, t=4.67, p=$ $.001)$, whereas the L1 reading predictor did not $(\beta=-.094 ; t=-.51, p>.10)$.

In summary, for the HiL2 group, the significant predictor of L2 reading ability was L1 reading ability, whereas for the LoL2 group, the significant predictor was L2 knowledge. It was on the basis of similar results that Clarke (1980) proposed his L2 threshold hypothesis, according to which a level of language knowledge below some critical threshold would be inadequate for the transfer of reading skills from the L1 to the L2.

\section{Question 3}

Does the absence of $L 1$ reading practice significantly affect the transfer of reading skills from L1 to L2?

The third main question we addressed was whether, as expected by Hacquebord's hypothesis, there would be a decrease over time in the influence of L1 reading ability on L2 reading ability among readers who did not maintain their L1 reading skills. In order to answer this question, we assigned the participants to one of two groups according to whether they were active or nonactive readers of their L1. Participants who, on the questionnaire administered at each testing time, indicated that they read only between 0 and 15 minutes per week in their L1 were assigned to the nonactive in L1 reading group. Participants who indicated that they read for 1 hour or more per week in their L1 were classified as active readers in L1. With this classification, the total number of cases was reduced to 47 . In order to distinguish the two groups as clearly as possible, we dropped the data for 2 individuals who reported that they read 30 minutes per week and for 1 participant who did not answer the question.

Our first analysis involved the relationship between L1 reading ability and L2 reading ability at Times 1 and 2. The most important comparisons concern the data for the nonactive L1 readers. For this group, the correlation between the two variables was significant at both times (Time

TABLE 5

Multiple Regression: L2 Reading Ability as a Function of L1 Reading Ability and L2 Knowledge at Time 2 for the High and Low L2 Knowledge Groups

\begin{tabular}{|c|c|c|c|c|c|}
\hline Variable & $\begin{array}{c}\text { Parameter } \\
\text { Estimate }\end{array}$ & $\beta$ & $t$ & $R^{2}$ & $F$ \\
\hline \multicolumn{6}{|l|}{$\begin{array}{l}\text { High L2 Knowledge } \\
(n=18)\end{array}$} \\
\hline L1 Reading Ability & .90 & .67 & $3.62 * * *$ & \multirow{3}{*}{.50} & \multirow{3}{*}{$7.61^{* *}$} \\
\hline L2 Knowledge & .03 & .14 & .78 & & \\
\hline $\begin{array}{l}\text { Low L2 Knowledge } \\
(n=14)\end{array}$ & & & & & \\
\hline L1 Reading Ability & -.07 & -.09 & -.51 & \multirow[b]{2}{*}{.68} & \multirow[b]{2}{*}{$11.90 * *$} \\
\hline L2 Knowledge & .08 & .86 & $4.67 * * *$ & & \\
\hline
\end{tabular}

Note. $d f=2$.

$* * p<.006$. *** $p=.001$. 
TABLE 6

Correlations: L1 and L2 Reading Ability Correlations as a Function of L1 Reading Activity and Time of Testing

\begin{tabular}{llllc}
\hline \hline & & & \multicolumn{2}{c}{$95 \%$ Confidence Limits } \\
\cline { 4 - 5 } Variables & $n$ & $r$ & Lower & Upper \\
\hline Nonactive L1 Readers & & & & \\
L1 \& L2 Reading Ability, Time 1 & 18 & $.665^{* * *}$ & .288 & .863 \\
L1 \& L2 Reading Ability, Time 2 & 19 & $.626^{* *}$ & .239 & .843 \\
Active L1 Readers & & & & \\
L1 \& L2 Reading Ability, Time 1 & 22 & .205 & -.237 & .576 \\
L1 \& L2 Reading Ability, Time 2 & 24 & $.560^{* *}$ & .202 & .787 \\
\hline
\end{tabular}

$* * p<.005$. *** $p<.001$.

1: $r=.655, n=28, p<.001 ;$ Time 2: $r=.626$, $n=19, p=.004$; see Table 6$)$. The apparent stability of this significant correlation suggests that the transfer of reading skills persisted even in the absence of reading activity in the L1. This result contradicts Hacquebord's (1989) hypothesis that there would be a decrease in the influence of $\mathrm{L} 1$ reading ability on L2 reading ability among those failing to maintain active L1 reading skills. For the active group, the correlation between L1 and L2 reading abilities was not significant at Time $1(r=.205, n=22, p>.10)$, but it was significant by Time $2(r=.560, n=$ $24, p=.004$ ).

Finally, we conducted an analysis of variance for mean L2 reading ability scores of active and nonactive L1 readers. For this analysis, we used only data from those participants whose status as active or nonactive L1 readers did not change during the course of the year $(n=14$ for each group). For these analyses, we recalculated $z$ scores for the two texts in a given language collapsed for Time 1 and Time 2, instead of separately at each time, to allow for a measure of change in reading ability across time.

Between Time 1 and Time 2, the nonactive readers showed a mean overall drop in their L2 reading ability scores (from .436 to .349), whereas the active readers had an overall gain (from -.382 to .567 ; see Table 7 ). A $2 \times 2$ repeated analysis of variance with the between factor Group (active, nonactive readers) and within factor Time (Time 1 , Time 2) revealed that this interaction effect was significant, $F(1,26)=6.03, M S E=3.756, p=$ .021 , eta squared $=.188$. The result suggests that active maintenance of $\mathrm{L} 1$ reading leads to improvement in $\mathrm{L} 2$ reading ability.

To explore whether some other variables could be responsible for this effect, we conducted additional tests. Three $t$ tests revealed no difference between the active and nonactive groups in L2 knowledge either at Time 1, $t(26)=-.725, p>$ .10 , or at Time 2, $t(26)=.089, p>.10$, nor in time spent reading the $\mathrm{L} 2, t(26)=.473, p>.10$. We redid the analysis of variance adjusted for the covariation of L2 knowledge and time spent reading in L2. The Group by Time interaction remained significant, $F(1,24)=6.250, M S E=$ $3.618, p=.02$, eta squared $=.207$. This result indicates that the significantly greater gains in L2 reading ability by the active readers in comparison to the nonactive readers cannot be explained by differences in the participants' knowledge of French or by the time they spent reading it.

\section{GENERAL DISCUSSION}

The results of this study confirmed the main observation of most previous studies in this area, that both L2 knowledge and L1 reading ability

TABLE 7

L2 Reading Ability at Time 1 and Time 2 for Learners Whose Status as Active and Nonactive L1 Readers Remained Unchanged over Time

\begin{tabular}{lcc}
\hline \hline Variables & Time 1 & Time 2 \\
\hline Nonactive L1 Readers $(n=14)$ & .436 & .349 \\
Active L1 Readers $(n=14)$ & -.382 & $.567 *$ \\
\hline
\end{tabular}

Note. Reading ability is shown here in z-score units (see text).

* Interaction effect significant: $F(1,26)=6.03, M S E=3.756, p=.021$. 
affect L2 reading ability. This finding was apparent in the significant correlations between L2 reading ability and L2 knowledge and L1 reading ability. Multiple regression analysis showed both as significant predictors at Time 2, but only L2 knowledge was significant at Time 1. At Time 2, L2 knowledge was significantly greater than at Time 1, and both $\mathrm{L} 1$ reading ability and L2 knowledge were significant predictors of L2 reading ability. This finding is consistent with Clarke's (1980) threshold hypothesis that one must achieve a sufficient level of knowledge in L2 before transfer of $\mathrm{L} 1$ reading skills can take place. Certainly by Time 2 , most participants would be expected to have improved in L2 knowledge as a result of having studied French and having lived in a French language environment for an additional year.

This view that a certain level of L2 knowledge is a necessary condition for $\mathrm{L} 1$ reading ability to predict L2 reading ability received support in the patterns that emerged in other analyses. For example, in one set of analyses, at both Time 1 and Time 2, data for participants with a lower L2 knowledge achievement level revealed the same pattern as described above, namely, L2 knowledge was a significant predictor of L2 reading, but L1 reading was not. Data for those participants with a higher L2 knowledge achievement level revealed a different pattern. At Time 1, neither factor was a significant predictor, but at Time 2, L1 reading ability emerged as the sole significant predictor, as expected by the threshold hypothesis. These participants had high levels of achievement in L2 and the benefit of a year of saturation in a French-language milieu. The results indicated that they had, in general, achieved a threshold level of L2 ability, whereby $\mathrm{L} 1$ reading skills would contribute to L2 reading. At this point, however, L2 knowledge did not appear to account for much of the variance in L2 reading, presumably because once the threshold level was achieved, individual differences in knowledge no longer had much impact on skill in reading simple texts (but could, of course, make a difference with respect to other L2 language skills, such as writing, complex speaking tasks, etc.). Thus, these data are fully consistent with the threshold hypothesis.

Hacquebord (1989) proposed that practice in L1 reading needs to be maintained so that $\mathrm{L} 1$ reading skills can transfer and play a supportive role in L2 reading. If this idea is correct, then one would expect L1 reading to be a significant predictor of $\mathrm{L} 2$ reading for active $\mathrm{L} 1$ readers and to a greater extent than for nonactive L1 readers, for whom the correlations between L1 and L2 reading ability should become nonsignificant over time. Given the results above, we should expect to have seen this result especially at Time 2 , after the nonactive participants had undergone a longer period without reading their L1.

Our results revealed a different pattern: Nonactive readers in L1 showed continuous influence of L1 reading ability on L2 reading ability. This finding seems to contradict Hacquebord's (1989) hypothesis and suggests that failure to maintain active L1 reading skills does not necessarily prevent their transfer to the L2. However, those participants who actively maintained L1 reading actually showed a large and significant improvement in L2 reading from Time 1 to Time 2, whereas the nonactive L1 readers did not show improvement. In combination, these results suggest that even though reading practice in the L1 is not necessary for the transfer of reading skills, such practice seems to enhance the effectiveness of the transfer. The further finding that improvement in reading ability from Time 1 to Time 2 was not attributable to L2 knowledge or to reading practice in the L2 further underscores the point.

The present findings raise a number of interesting possibilities for future research. For example, it will be important to investigate how well the results reported here generalize to other populations and to L1-L2 language pairs of varying degrees of orthographic similarity. It would also be useful to have more fine-grained data about the amount and nature of the participants' L1 reading activities because there may have been important relationships between L1 reading activities and L2 reading ability that were overlooked in the present study. Future research could also explore other approaches to data analysis. One anonymous reviewer, for example, proposed "response surface" analyses involving examination of the shape of a surface fitted to a scatterplot in a 3-dimensional, L1 Reading Ability by L2 Knowledge by L2 Reading Ability space. Such analyses afford the possibility of locating threshold points and values of the L1 reading ability and L2 knowledge variables associated with optimal L2 reading success. These response surface analyses could also be conducted as a function of L1 reading activity level. This approach to data analysis permits interpretations that look beyond significance levels of linear coefficients obtained in multiple regression, a limitation of the present study. Such analyses would, of course, require larger samples than were used here.

Although we did not, in this research, address pedagogical issues regarding how to promote L2 reading skill by harnessing L1 reading skills, the 
results raise some interesting hypotheses for future exploration. Given that the findings suggest that positive transfer occurs from L1 to L2 reading under particular circumstances, namely, when the learner has achieved a threshold level of knowledge of the L2 and is maintaining a threshold level of reading activity in the $\mathrm{L} 1$, it would be interesting to examine the impact of introducing incentives for $\mathrm{L} 1$ reading to students who have attained the threshold level of knowledge of the L2 in order to see if their L2 reading progress surpasses that of other students who are not specifically encouraged to maintain L1 reading activities.

Future research should investigate, in more qualitative terms than was possible here, which aspects of reading are affected by transfer. For example, L1 reading maintenance might enhance the transfer of top-down reading strategies concerned with the integration of information across sentences and text, as opposed to enhancing more local processing concerned with single word recognition and grammatical parsing. This effect might be expected because high-level crosstext integration of information is likely to require relatively similar processes across languages, whereas local-level processing is likely to be relatively more language specific.

Future research could also focus on how transfer of L1 reading skills to L2 reading actually builds on a threshold level of knowledge of L2 vocabulary and grammar, as the present results indicate, and whether it requires, in addition to this knowledge, the ability to access and implement it with a high degree of fluency (e.g., automatically, as described in Segalowitz, 2000).

Finally, future research should address more directly the possible role played by mediating variables, such as motivation to learn, general interest in linguistic activities, and the relationship between specific L1s and L2s, in terms of the cognitive demands they each make on the reader by virtue of the orthographic transparency of the writing systems involved and the degree of similarity between them. By greatly increasing our understanding of the role played by the many complex variables involved in learning to read a L2, it may become possible to enhance L2 reading instruction by systematically harnessing already existing skills in L1 reading.

\section{ACKNOWLEDGMENTS}

The study reported here was part of the first author's doctoral thesis, co-supervised by the other two authors and supported by a doctoral fellowship from the Québec Ministry of Education (FCAR). The research was also supported in part by a grant to the second author from the Québec Ministry of Education (FCAR) and the Natural Sciences and Engineering Research Council of Canada (NSERC).

NOTE

${ }^{1}$ Hacquebord (1989) conducted her study with approximately 50 young bilingual students who lived in the Netherlands, a L2 environment for them. They averaged 13.9 years of age, spoke Turkish as their L1 and Dutch as their L2, and had immigrated before the age of 7 , most of them before the age of 4 . They had a high level of mastery of their L2, given that $57 \%$ had gone through 6 years of elementary school in Dutch. Testing took place in two sessions separated by a 2-year interval. Correlations for the first series of tests indicated a strong relation between L2 proficiency and L2 reading ( $r=$ $.74, p<.001)$ and between L1 reading and L2 reading $(r=.40, p<.001)$. The latter correlation was not significant for the second session $(r=.09$, ns), whereas the former correlation remained significant and identical to that found for a control group of native speakers $(r=$ $.54, p<.001)$. Unfortunately, as noted by Bossers (1991), assessing the relative influence of the independent variables was not possible in the absence of multiple regression analyses.

\section{REFERENCES}

Alderson, J. C. (1980). Native and nonnative speaker performance on cloze tests. Language Learning, 30 , 59-76.

Alderson, J. C. (1984). Reading: A reading problem or a language problem? In J. C. Alderson \& A. H. Urquhart (Eds.), Reading in a foreign language (pp. 1-24). Essex, UK: Longman.

Anderson, J. (1976). Psycholinguistic experiments in foreign language testing. Santa Lucia, Australia: University of Queensland Press.

Bachman, L. F. (1982). The trait structure of cloze test scores. TESOL Quarterly, 16, 61-70.

Bachman, L. F. (1985). Performance on cloze tests with fixed-ratio and rational deletions. TESOL Quarterly, 19, 535-556.

Bernhardt, E. B., \& Kamil, M. (1995). Interpreting relationships between L1 and L2 reading: Consolidating the linguistic threshold and the linguistic interdependence hypotheses. Applied Linguistics, 16, 15-34.

Bormuth, J. R. (1967). Comparable cloze and multiplechoice comprehension test scores. Journal of Reading, 10, 291-299.

Bossers, B. (1991). On thresholds, ceilings and short-cir- 
cuits: The relation between $\mathrm{L} 1$ reading, L2 reading and L2 knowledge. Revue de l'AILA, 8, 45-61.

Brière, E. J., Clausing, G., Senko, D., \& Pincell, E. (1978). A look at cloze testing across languages and levels. Modern Language Journal, 62, 23-26.

Brisbois, J. E. (1995). Connections between first- and second-language reading. Journal of Reading Behavior, 27, 565-584.

Carrell, P. L. (1991). Second language reading: Reading ability or language proficiency? Applied Linguistics, 12, 159-179.

Chihara, T., Oller, J. W., Weaver, K. A., \& Chávez-Oller, M. A. (1977). Are cloze items sensitive to constraints across sentences? Language Learning, 27, 63-73.

CIRB: Centre International de Recherche sur le Bilinguisme. (1976). Test Laval Formules B et C. Québec, Canada: Presses de l'Université Laval.

Clarke, M. A. (1980). The short-circuit hypothesis of ESL reading or when language competence interferes with reading performance. Modern Language Journal, 64, 203-209.

Cziko, G. A. (1978). Differences in first and second language reading: The use of syntactic, semantic, and discourse constraints. Canadian Modern Language Review, 34, 473-489.

Fecteau, M. L. (1999). First- and second-language reading comprehension of literary texts. Modern Language Journal, 83, 475-493.

Hacquebord, H. (1989). Tekstbegrip van Turkse en Nederlandse leerlingen in het voortgezet onderwijs [Text comprehension of Turkish and Dutch students in secondary education]. Dordrecht, the Netherlands: Foris.

Henry, G. (1975). Comment mesurer la lisibilité [How to measure readability]. Bruxelles: Éditions Labor.

Jonz, J. (1987). Textual cohesion and second language comprehension. Language Learning, 37, 409-438.
Jonz, J. (1990). Another turn in the conversation: What does cloze measure? TESOL Quarterly, 24, 61-83.

Jonz, J., \& Oller, J. W. (1994). A critical appraisal of related cloze research. In J. W. Oller \& J. Jonz (Eds.), Cloze and coherence (pp. 371-408). Lewisburg, PA: Bucknell University Press.

Klein-Braley, C., \& Raatz, U. (1984). A survey of research on the C-test. Language Testing, 1, 134-146.

Lee, J.-L., \& Lemonnier-Schallert, D. (1997). The relative contribution of L2 language proficiency and L1 reading ability to L2 reading performance: A test of the threshold hypothesis in an EFL context. TESOL Quarterly, 31, 713-739.

Pichette, F. (1995). Lecture en langue seconde [Reading in a second language]. In J. Audette, M.-A. Bélanger, A. Bourcier, I. Dion, P. Larrivée, J. Nicole, F. Pichette, \& E. Rosales (Eds.), Actes des 9e Journées de linguistique [Proceedings of the 9th Linguistics Days] (pp. 105-110). Sainte-Foy, Québec, Canada: Presses de l'Université Laval.

Roller, C. M. (1988). Transfer of cognitive academic competence and L2 reading in a rural Zimbabwean primary school. TESOL Quarterly, 22, 303-328.

Segalowitz, N. (2000). Automaticity and attentional skill in fluent performance. In H. Riggenbach (Ed.), Perspectives on fluency (pp. 200-219). Ann Arbor, MI: University of Michigan Press.

Shanahan, T., Kamil, M., \& Tobin, A. (1982). Cloze as a measure of intersentential comprehension. Reading Research Quarterly, 17, 229-255.

Taillefer, G. (1996). L2 reading ability: Further insight into the short-circuit hypothesis. Modern Language Journal, 80, 461-477.

Wagner, D., Spratt, J., \& Ezzaki, A. (1989). Does learning to read in a second language always put the child at a disadvantage? Some counterevidence from Morocco. Applied Psycholinguistics, 10, 31-48. 


\section{Correlations}

$\begin{array}{llll}M & (S D) & \text { L1R } & \text { L2K }\end{array}$

A. Means and Correlations for L2 Reading Ability (L2R), L1 Reading Ability (L1R), and L2 Knowledge (L2K) at Time 1 and Time 2

Time $1(N=50)$

$\begin{array}{ccccc}\text { L1R } & 40.53 & (13.79) & 1.000 & \\ \text { L2K } & 48.64 & (14.94) & 0.603 & 1.000 \\ \text { L2R } & 38.62 & (16.55) & 0.511 & 0.647 \\ \text { Time 2 }(N=43) & & & & \\ \text { L1R } & 41.04 & (16.49) & 1.000 & \\ \text { L2K } & 51.77 & (16.25) & 0.492 & 1.000 \\ \text { L2R } & 43.28 & (15.86) & 0.601 & 0.556\end{array}$

B. Means and Correlations for L2 Reading Ability (L2R), L1 Reading Ability (L1R), and L2 Knowledge (L2K) at Time 1 for High and Low L2 Knowledge Subgroups

High $(n=16)$

$\begin{array}{lrrrr}\text { L1R } & 50.90 & (6.78) & 1.000 & \\ \text { L2K } & 66.06 & (6.84) & 0.198 & 1.000 \\ \text { L2R } & 49.10 & (11.62) & 0.230 & 0.512 \\ \text { Low }(n=17) & & & & \\ \text { L1R } & 32.14 & (14.70) & 1.000 & \\ \text { L2K } & 32.35 & (6.25) & 0.504 & 1.000 \\ \text { L2R } & 24.40 & (13.44) & 0.599 & 0.693\end{array}$

C. Means and Correlations for L2 Reading Ability (L2R), L1 Reading Ability (L1R), and L2 Knowledge (L2K) at Time 2 for High and Low L2 Knowledge Subgroups

High $(n=18)$

$\begin{array}{lrrrr}\text { L1R } & 46.51 & (15.25) & 1.000 & \\ \text { L2K } & 67.11 & (5.66) & 0.177 & 1.000 \\ \text { L2R } & 51.22 & (17.76) & 0.695 & 0.262 \\ \text { Low }(n=14) & & & & \\ \text { L1R } & 35.49 & (16.81) & 1.000 & \\ \text { L2K } & 32.21 & (7.47) & 0.391 & 1.000 \\ \text { L2R } & 34.53 & (12.19) & 0.242 & 0.823\end{array}$

